\title{
Transposition of a stimulus generalization gradient along an auditory intensity continuum'
}

SCOT BLUE AND FREDERICK W. HEGGE

BROWN UNIVERSITY

\begin{abstract}
Four male, albino rats were trained on a 9-valued auditory intensity discrimination (a maintained generalization paradigm) with the most intense stimulus as the $\mathrm{S} D$. After seven days of training all stimuli were increased in intensity by $45 \mathrm{db}$. Three of the four Ss displayed complete tranposition of the entire generalization gradient.

\section{Problem}

The majority of the data relating to transposition has been gathered using visual stimuli along the object size and brightness dimensions (for a recent review of some of the literature see Hebert \& Krantz, 1965). To date, little work using auditory continua has been done (McKee \& Riley, 1962; Riley \& McKee, 1963; and Riley, McKee, \& Hadley, 1964), and even less work has employed an operant methodology (Honig, 1962)。

Within the framework of a broader study it was possible to assess the effects of transposing an entire maintained generalization gradient along an auditory intensity continuum. The present experiment was not designed specifically to study transposition. However, the results are clear enough to suggest that research concerned with the transposition of stimulus control over the behavior of an animal, using an auditory intensity continuum and the operant lever-pressing response, would be fruitful.

Method
\end{abstract}

Ss were four Sprague-Dawley derived male, albino rats between 180 and 200 days old at the start of the experiment. Ss were reduced to $80 \%$ of their ad libitum weights and so maintained. Sound shielded enclosures equipped with speaker, retractable bar, water bottle, pellet dispenser, and food tray were used. The programming of sound stimuli, reinforcements, and the recording of responses was automated and controlled from an adjacent room. The stimuli employed were $4.0 \mathrm{kHz}$ tones ranging in intensity from $100 \mathrm{db}$ to $15 \mathrm{db}$ S.P.L. in $5 \mathrm{db}$ steps. These tones were presented with a 4.0 sec. period, the duty cycle consisting of 1.5 sec. ON-2.5 sec. OFF. Intensity changes were programmed to occur only during OFF times. A more detailed account of the equipment is given in Pierrel \& Sherman (1960).

There was an initial day of bar-training in which 100 reinforcements were received on an FI $10 \mathrm{sec}$. schedule, followed by two days ( $2 \mathrm{hr} . /$ day) of training on the VI 1 min. schedule which was to be in effect during subsequent $S^{D}$ presentations. During these sessions the stimulus which was to be the training $\mathrm{S}^{D}$ was present at all times. Daily $4 \mathrm{hr}$. sessions of multi-S ${ }^{\Delta}$ (generalization) training were begun on the following day. During Day 1-7 of this training the $\mathrm{S}^{\mathrm{D}}$ was $55 \mathrm{db}$ and the $\mathrm{S}^{\Delta_{\mathrm{S}}}$ ranged from 50 to $15 \mathrm{db}$ in $5 \mathrm{db}$ steps. Fifteen minutes of each hour was devoted to 1-3 min. $\mathrm{S}^{\mathrm{D}}$ presentations, and the remaining time was divided into $1.0,1.6$, and $3.0 \mathrm{~min} . \mathrm{S}^{\Delta}$ presentations. Over the $4 \mathrm{hr}$. session, a total of $60 \mathrm{~min}$. was devoted to $\mathrm{S}^{\mathrm{D}}$ and $22.4 \mathrm{~min}$. to each $\mathrm{S}^{\Delta}$. The disproportionate amount of $\mathrm{S}^{\mathrm{D}}$ was compensated for in the data analysis by multiplying the $\mathrm{S}^{D}$ totals by 0.37 . Day 8 constituted the transposition test. All of the stimuli were increased in intensity by $45 \mathrm{db}$. The continuum now ran from an $S^{D}$ at $100 \mathrm{db}$ through the $\mathrm{S}^{\Delta} \mathrm{S}$ to the lowest intensity of $60 \mathrm{db}$ which was $5 \mathrm{db}$ more intense than the training $\mathrm{s}^{\mathrm{D}}$.

\section{Results}

Sets of generalization gradients plotted in terms of median percent $\mathrm{S}^{\mathbf{D}}$ for the four animals appear in Fig. 1. The Day 1-first hour gradient shows that there was an initial tendency to respond more to the less intense stimuli. The low rate at $55 \mathrm{db}$ can be accounted for by post-reinforcement pauses that sharply depressed overall $\mathrm{S}^{\mathrm{D}}$ rates during the early phase of training. By Day 5, the gradients had begun to stabilize. The greatest amount of responding occurred in the presence of $\mathrm{S}^{\mathbf{D}}$ and an orderly decrease in rate occurred as the stimuli became less intense.

The first and fourth hour gradients from Day 6, 7, and 8 are shown to indicate the comparability of the response distribution over the last two days of training and the first day of transposition. The behavior during the first hour (solid line) of each session

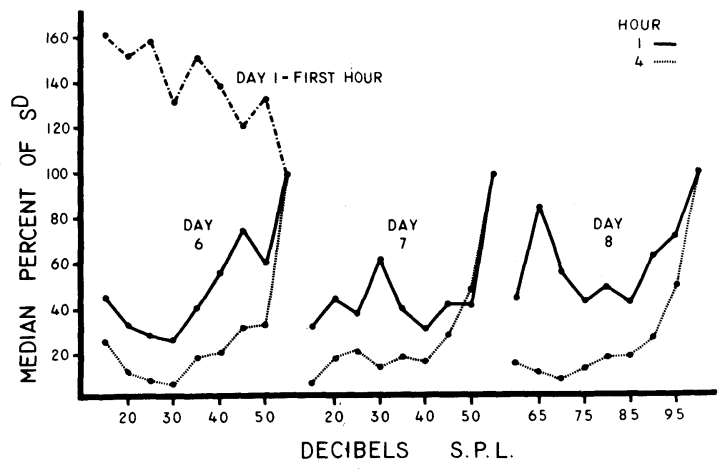

Fig. 1. Generalization gradients plotted in terms of median percent of $S^{D}(N=4)$, for the first hour of the first day of training, and the first and fourth hours of the last two days of training (Day 6 and 7 ) and the first day of transposition (Day 8). All sessions were four hours in length. 
showed more variability and higher $\mathrm{S}^{\Delta}$ rates than the subsequent $3 \mathrm{hr}$. This effect mitigates against transposition.

If the Ss were under the control of the absolute intensive properties of the training $\mathrm{S}^{\mathrm{D}}$ on Day 7 , the : one would expect a relatively high rate of response to be controlled by the $60 \mathrm{db} \mathrm{S}^{\Delta}$ on Day 8 . Table 1 shows that this is not the case. In this table individual response rates are compared for performances on the first Day 7 presentation of the least intense training $\mathrm{S}^{\Delta}$ and the training $\mathrm{S}^{\mathrm{D}}$ with the first Day 8 presentation of the least intense transposed $S^{\Lambda}$ and the transposed $\mathrm{S}^{\mathrm{D}}$. Rates during the $60 \mathrm{db}$ presentation are equal to, or somewhat higher than, those in the comparable $15 \mathrm{db}$ interval, but much lower than the rates under $55 \mathrm{db}$ in three of the four animals. Subject $\mathrm{H}$ is the exception. This animal showed the least transposition facility; however, he also produced the least orderly gradients during the initial training.

\section{Discussion}

Transposition methodologies are of value when used to provide an operational definition of the stimuli which control the behavior of an organism at a given stage of training, or, as others have often phrased it, transposition can indicate "what is learned" by an animal. In attempting to delineate the nature of experimental stimulus control, some investigators have emphasized the absolute properties of the individual stimuli employed, while others have stressed the relationships between the various stimuli. Auditory stimuli, programmed according to a multiple schedule, would appear well suited to the production of relational control. In a simple 2-valued schedule (one $\mathrm{S}^{\mathrm{D}}$, one $\left.S^{i}\right)$ the stimuli are presented to the animal sequentially, and a change in intensity is always accompanied by a change in reinforcement probability. If the more intense stimulus is $\mathrm{S}^{\mathrm{D}}$, an incremental change would signal the onset of $\mathrm{S}^{\mathrm{D}}$, and a decremental change would indicate the onset of $\mathrm{S}^{\Delta}$. If the two intensities are invariant over the course of training, it is equally likely that the discrimination could be based on the absolute intensive properties of the stimuli. Both types of control might be expected to develop within a group of animals when they are exposed to the conditions described above.

The notion of relational, rather than absolute, control ove responding is easily extended to the present experiment. Since $S^{D}$ was always the most intense of a set of stimuli, it was always preceded by a less intense $\mathrm{S}^{\Delta}$. Thus an intensity increment might signal an increase in the probability of reinforcement. Conversely, any decrease in stimulus intensity indicated zero reinforcement probability. For any given stimulus, the greater its intensive proximity to $S^{D}$, the higher was the probability that, on any given presentation, it was preceded by a less intense stimulus, and therefore, at this time could have relational $\mathrm{S}^{\mathrm{D}}$ properties which would control a relatively high rate of response in its presence. All stimuli except $\mathrm{S}^{\mathrm{D}}$, the most intense,
TABLE I

Comparison of Response Rates per Minute for Most and Least Intense Stimuli during the Final Day of Training (Day 7) and the

First Day of Transposition (Day 8). Data is from the First Presentations of the Stimuli during the Session only

\begin{tabular}{ccccc} 
Subject & $15 \mathrm{db} /$ Day 7 & $55 \mathrm{db} /$ Day 7 & $60 \mathrm{db} /$ Day 8 & $100 \mathrm{db} /$ Day 8 \\
\hline$E$ & 7.0 & 26.7 & 9.0 & 35.7 \\
$F$ & 2.0 & 36.3 & 11.0 & 19.0 \\
$G$ & 10.0 & 30.3 & 10.0 & 28.7 \\
$H$ & 8.0 & 8.7 & 12.0 & 18.3 \\
\hline Median & 7.5 & 28.5 & 10.5 & 23.9 \\
\hline
\end{tabular}

would also exhibit relational $\mathrm{S}^{\Delta}$ properties graded as a direct function of the distance from $S^{D}$. The foregoing analysis can account for the orderly response gradients observed in this experiment during initial training.

That at least three of the four animals were under the control of these relational properties of the stimuli seems apparent from their performance on the transposition test. If the behavior were controlled by the absolute intensive properties of the $55 \mathrm{db} \mathrm{S}^{\mathrm{D}}$, one would expect a high degree of generalized strength to $60 \mathrm{db}$. If, however, behavior was controlled by relational properties of the stimuli, one would expect little strength in the presence of $60 \mathrm{db}$ since it had never been preceded by a less intense stimulus during transposition. The latter, relational interpretation, appears to be more convincing.

A word must be said about the peak at $65 \mathrm{db}$ in the first hour-Day 8 gradient. A gradient summation hypothesis has been suggested which would cast doubt on the relational interpretation (e.g., Spence, 1937). The most frequently mentioned gradient shapes (tent, dome, gaussian) were investigated and no excitation-inhibition interaction could be found which would generate a peak only at $65 \mathrm{db}$. Therefore, this perturbation seems best explained by an appeal to the consistently higher variability observed during the first hour of each session.

\section{References}

Hebert, J. A., \& Krantz, D. L. Transposition: a reevaluation. Psychol. Bull., 1965, 63, 244-257.

Honig, W. K. Prediction of preference, transposition, and transposition-reversal from the generalization gradient. J. exp. Psychol., 1962, 64, 239-248.

McKee, J. P., \& Riley, D. A. Auditory transposition in six year old children. Child Develpm., 1962, 33, 469-476.

Pierrel, R., \& Sherman, J. G. Generalization of auditory intensity following discrimination training. J. exp. Anal. Behav., 1960, $3,313-322$.

Riley, D. A., \& Mckee, J. P. Pitch and loudness discrimination in children and adults. Child Develpm., 1963, 34, 471-482.

Riley, D. A., McKee, J. P., \& Hadley, R. W. Prediction of auditory discrimination learning and transposition from children's auditory ordering ability. J. exp. Psychol., 1964, 67, 324-329.

Spence, K. W. The differential response of animals to stimuli varying within a single dimension. Psychol. Rev., 1937, 44, 430-444.

\section{Note}

1. This research was supported by USPHS Grant HD-00928, Rosemary Pierrel, principal investigator. 